\title{
Mitral Valve Malfunction of a St. Jude Medical Prosthetic due to Pannus Formation and Thrombosis
}

\author{
Takashi Ogino, ${ }^{1}$ Kazuhiro Sakata, ${ }^{2}$ Toshiharu Yamagishi, ${ }^{2}$ \\ Shuichi Hagiwara, ${ }^{3}$ Kiyohiro Ohshima, ${ }^{3}$ Yuichi Iino, ${ }^{3}$ \\ Satoshi Ohki, ${ }^{4}$ Toru Takahashi, ${ }^{4}$ Izumi Takeyoshi ${ }^{4}$ \\ and Yasuo Morishita ${ }^{4}$
}

\begin{abstract}
Published studies report the incidence of pannus formation with the St. Jude Medical ${ }^{\mathrm{R}}$ prosthetic mitral valve to be $0.02 \%$. The following report details a mitral valve malfunction due to pannus formation and thrombosis in a 70-year-old woman which occurred 16 months after the initial operation $\left(\mathrm{SJM}^{\mathrm{R}} 27 \mathrm{~mm}\right.$ ) using Dacron-cuff. A second replacement using a mitral valve prosthesis ( $\mathrm{SJM}^{\mathrm{R}} 27 \mathrm{~mm}$ ) using Teflon-cuff was successfully performed and the postperative course was uneventful. The possibility of pannus formation of St. Jude Medical ${ }^{\mathrm{R}}$ aortic valve and its mechanism are discussed in this report. (Kitakanto Med J 2012;62:301 303)
\end{abstract}

Key words : $\mathrm{SJM}^{\mathrm{R}}$, mitral valve, malfunction, pannus

\section{Introduction}

The St. Jude Medical $\left(\mathrm{SJM}^{\mathrm{R}}\right)$ valve has been one of the most reliable cardiac valve prostheses for over 2 decades due to its excellent durability, thromboresistance, and hemodynamic performance. According to our review of the literature, several authors have reported malfunction of the SJM valve since its introduction in 1977, but few reports were found indicating malfunction in the mitral position due to pannus formation and thrombosis. Our report describes the case of 70 -year-old woman with St. Jude Medical ${ }^{\mathrm{R}}$ mitral valve malfunction due to pannus formation and thrombosis. We also discuss the contributing factors of this condition.

\section{Case Reports}

A 70-year-old woman underwent a mitral valve replacement involving a SJM $27 \mathrm{~mm}$ (Dacron-cuff) mitral prosthesis in January, 1999. The postoperative course was uneventful, and postoperative anticoagula- tion therapy was administered using coumadin (Warfarin). There had been no occurance of congestive heart failure until March, 2000 when the patient complained of chest pain. The patient was admitted to our hospital in March, 2000 with the a complaint of dizziness and dyspnea. Cinefluoroscopic examination showed slight aortic and mitral regurgitation. Echocardiographic examination revealed restricted motion of valve opening, trivial mitral stenosis, a pressure half time of 208 mseconds, mitral valve area of $1.06 \mathrm{~cm}^{2}$ and left ejection fraction of $41 \%$. Hemolysis was not suspected based on the following lab values: T-Bil of $0.6 \mathrm{mg} / \mathrm{dl}$, GOT of $25 \mathrm{IU} / 1$ and LDH of 550 IU/1. Anticoagulation therapy initiated immediately. Additional echocardiographic examinations showed no improvement in valve motion. We therefore concluded that the restricted valve motion might be due to pannus formation and performed a mitral valve replacement.

Entering through a median stenotomy, the ascending aorta and both venae cavae were cannulated with

1 Department of Intensive Care, National Hospital Organization Takasaki General Medical Center, 36 Takamatsu-cho, Takasaki, Gunma 370-0829, Japan 2 Department of Cardiovascular Surgery, National Hospital Organization Takasaki General Medical Center, 36 Takamatsu-cho, Takasaki, Gunma 370-0829, Japan 3 Department of Emergency Medicine, Gunma University Graduate School of Medicine, 3-39-22 Showa-machi, Maebashi, Gunma 371-8511, Japan 4 Department of Thoracic and Visceral Organ Surgery, Gunma University Graduate School of Medicine, 3-39-22 Showa-machi, Maebashi, Gunma 371-8511, Japan Received: May 17, 2012

Address : TAKASHI OGINO Department of Intensive Care, National Hospital Organization Takasaki General Medical Center, 36 Takamatsu-cho, Takasaki, Gunma 370-0829, Japan 
(A)
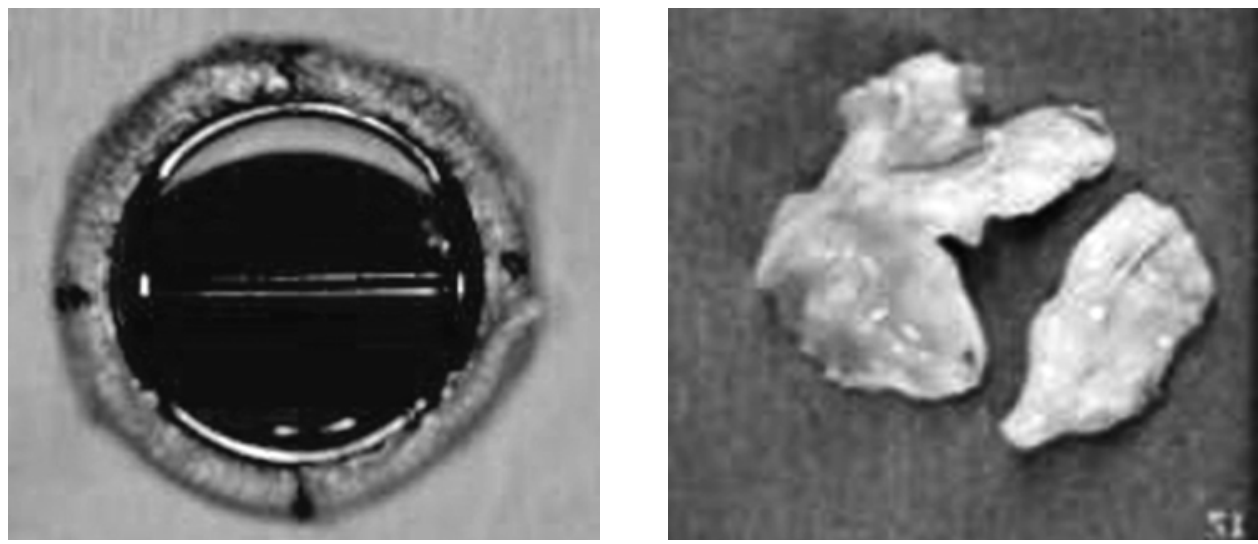

(A)

Fig. 1 Excised $\mathrm{SJM}^{\mathrm{R}}$ valve (A) and pannus formed on valve leaflet (B)

straight cannulas and cardiopulmonary bypass was established. After moderate systemic hypothermia, the ascending aorta was cross-clamped and cold blood cardioplegia was administered. Using a transseptal approach, circumferential pannus on the $\mathrm{SJM}^{\mathrm{R}}$ was observed in the left atrium. Both pannus and thrombi were prominent at the pivot of the leaflets, which we suspected was the cause of the restricted motion of the valve opening (Fig. 1). Following removal of the implanted valve, a $27 \mathrm{~mm} \mathrm{SJM}{ }^{\mathrm{R}}$ (Teflon-cuff) prosthesis was implanted. The patient was easily weaned from cardiopulmonary bypass, and the postoperative course has been uneventful for 10 years.

\section{Disscussion}

The St. Jude Medical valve prosthesis is the most widely used valve replacement in the world. Some published literature has reported the incidence of pannus formation with the $\mathrm{SJM}^{\mathrm{R}}$ valve in the aortic position to be $0.03 \%$ to $0.14 \%$ and in the mitral position to be $0.02 \%$, with the incidence less frequent in the mitral position than in the aortic position. ${ }^{1,2}$ The morphology of pannus formation is not well known. Valve malfunction caused by pannus in association with thrombi was 59\% (pannus alone was $41 \%$ ) in patients with malfunction due to pannus formation after valve surgery, and a significant relationship between the pannus location and secondary thrombus location has been reported. ${ }^{3}$ Some coexisting factors may contribute to excessive tissue overgrowth. The design and biocompatibility of the prosthesis, the presence of irregular endothelial surfaces at the time of original valve placement, the surgical technique used, low-output condition, blood flow turbulence, pregnancy, endocarditis, and inadequate anticoagulation may all play a role in the development of pannus. Unfortunately, it is very difficult to assess the real role of these factors in pannus formation. ${ }^{4-10}$ The causes of pannus overgrowth are not yet identified. It is likely that a particular patient's intensified nonim- mune reaction against a foreign body together with other contributory factors such as low transvalvular flow may trigger pannus growth. Pannus overgrowth in this patient was detected on the inflow portion of the prosthesis and had developed over the holding case, resulting in valve malfunction.

In our patient, the different types of sewing cuffs were used; a Dacron-cuff in the first instance, and a Teflon-cuff the second time. The stitch of a Tefloncuff is rougher than that of a Dacron-cuff. One coexisting factor that contributed to pannus overgrowth at the mitral position is low-output. This patient had hypertension only, and low-output conditions might have existed and contributed to tissue overgrowth. After changing the type of sewing cuff, no pannus formation has occured for 10 years.

In conclusion, we have presented a rare case of St. Jude Medical ${ }^{\mathrm{R}}$ prosthetic mitral valve malfunction due to pannus formation and thrombosis. We believe that critical note should be taken considering the possibility of pannus formation on $\mathrm{SJM}^{\mathrm{R}}$ valves even in the mitral position.

\section{References}

1. Baudet EM, Pual V, McBride JT, et al. Long-term results of valve replacement with the St. Jude Medical prosthesis. J Thorac Cardiovasc Surg 1995; 109: 858-870.

2. Aoyagi S, Oryoji A, Nishi Y, et al. Long-term results of valve replacement with the St. Jude Medical valve. J Thorac Cardiovasc Surg 1994 ; 108 : 1021-1029.

3. Vitale N, Renzulli A, Agozzino L, et al. Obstruction of mechanical mitral prostheses: analysis of pathologic findings. Ann Thorac Surg 1997; 63: 1101-1106.

4. Kontos GJ, Schaff HV, Orszulak TA, et al. Thrombotic obstruction of disc valves : clinical recognition and surgical management. Ann Thorac Surg 1989; 48: 60-65.

5. Venugopal P, Kaul U, Iyer KS, et al. Fate of thrombectomized Bjork-Shiley valves. A long term cinefluoroscopic endocardiographic and hemodynamic evaluation. J Thorac Cardiovasc Surg 1986; 91 : 168-173.

6. Copans H, Lakier JB, Kinsley RH, et al. Thrombosed Bjork-Shiley mitral prosthesis. Circulation 1980; 61: 
169-174.

7. Wright JO, Hiratzka LF, Brandt B et al. Thrombosis of the Bjork-Shiley prothesis. J Thorac Cardiovasc Surg 1982; 82: 138-144.

8. Vitale N, Renzulli A, Cerasuolo F, et al. Prosthetic valve obstruction: thrombolysis versus operation. Ann Thorac Surg $1994 ; 57: 365-370$.
9. Jegier B, Jaszewski R, Lelonek M : Late outcome of mitral valve replacement with the Cross-Jones prosthesis 36 years after initial surgery. Cardiol J. 2011; 18: 698-700.

10. Osman F, Steeds R: Use of intra-cardiac ultrasound in the diagnosis of prosthetic valve malfunction. Eur $\mathrm{J}$ Echocardiogr. 2007 Oct ; 8 : 392-394. 